\title{
Dental implants in an orthodontically created spaces using NiTi open coil spring in anterior and premolar regions
}

\begin{tabular}{lll}
\hline Omar Fawzi Abduljabbar* & Omed I. Shihab ** & Othman A. Omer ** \\
\hline & Abstract &
\end{tabular}

Background and objective: Orthodontic space opening is a common treatment for congenitally missing teeth. Dental implants are often used to replace the missing tooth to establish ideal esthetics without restoring the adjacent teeth. This study aimed to investigate the outcome of implants placed in orthodontically created bone.

Methods: Fifty dental implants were used for rehabilitation of lost tooth/teeth in 30 patients after space creation using orthodontic treatment. Patients with congenital and traumatic missing tooth/teeth, who lost the space for accommodation of normal size crown, and patients with spacing were enrolled in the study. NiTi open coil spring was used for space creation. The patients were followed up clinically and radiographically (OPG).

Results: Out of 50 implants, the success rate was 78\% (39 implants). Eleven implants $(22 \%)$ failed to get osseointegration. Mean age of the patients was 26.33. Female patients constituted $63.33 \%$, and male patients $36.67 \%$. A new one replaced all the failed implants. Most of the failures were in the mandible.

Conclusion: Orthodontic treatment can be used as a type of osteodistraction method for provision of an acceptable amount of bone for dental implants. The quality of the gained bone can be improved by offering sufficient time for healing.

Keywords: Dental implants; NiTi open coil; Orthodontic; Space creation.

\section{Introduction}

The ability to recreate the sufficient amount of space is a fundamental factor. Orthodontic treatment plays an important role in providing the required space, using different mechanics for tooth movement. The single-tooth dental implant has become the most popular treatment modality for the replacement of missing lateral incisor. ${ }^{1-6}$ Various studies have shown the successful ossteointegration and long-term stability of restorations supported by single-tooth dental implants. ${ }^{7-}$ 9 Orthodontic space opening during adolescence is a popular treatment option for congenitally missing maxillary lateral incisors. In these situations, dental implants are usually used to replace the missing tooth to establish ideal esthetics and function without harvesting the adjacent teeth. The quality and quantity of alveolar bone and gingival tissues in potential implant placement sites are a major determinant of the long-term stability and success of the implant fixture. The primary stability of a dental implant is directly related to the amount of alveolar bone available at the time of implant placement. Implants should be placed in pre-existing bone, while regenerative bone in newly created spaces should not be relied on for primary support but merely to obtain coverage. ${ }^{10}$ Since all the published studies $^{1-6}$ have focused on lateral incisor replacement, this study aimed to find out the outcome of orthodontic space creation and dental implantation in areas other than lateral incisor.

\section{Methods}

Fifty dental implants were used for rehabilitation of lost tooth/teeth in 30

* Department of P.O.P, College of Dentistry, Hawler Medical University, Erbil, I raq.

** Department of Oral and Maxillofacial , College of Dentistry, Hawler Medical University, Erbil, I raq. 
patients, after space creation using wire creating a space of about 7-9 $\mathrm{mm}$ for orthodontic treatment. Patients with congenital and traumatic missing tooth/teeth, who lost the space for accommodation of normal size crown, and patients with spacing were enrolled in the study. Maxillary and mandibular anterior and premolar region were involved. Thorough diagnostic measures including clinical examination, casts, photographs and radiographs (OPG) were performed. The patients were informed about the procedure of orthodontic treatment, for recreating the space for lost tooth, and dental implants. After good control of oral hygiene measures, orthodontic treatment was started with straight arch wire mechanics (Roth 0.22). Starting leveling and alignment with a series of 14 , $18,16^{*} 22$ and $17^{*} 25 \mathrm{NiTi}$ wires for about 6 months followed by space creation for the missing tooth/teeth space using NiTi open the lateral incisors and about 8-10 mm for canines and premolars on both arches (Figure 1). Followed by a period of uprighting and torquing using $18^{\star} 25$ and $21^{*} 25$ both $\mathrm{NiTi}$ and stainless steel wires. After that a period of finishing and occlusion settling using light arch wires and inter arch elastic mechanics. After orthodontic space creation, the patient underwent implant surgery with the casual surgical protocol. During the drilling process, the created bone didn't show a noticeable degree of resistant (more spongy). In three cases granulation tissue was detected in the implant bed. Using periapical approach, the granulation tissues were curetted and the bony gap augmented by bone graft and implants were immediately installed. All the patients were recalled for completion of the treatment six months post surgery.

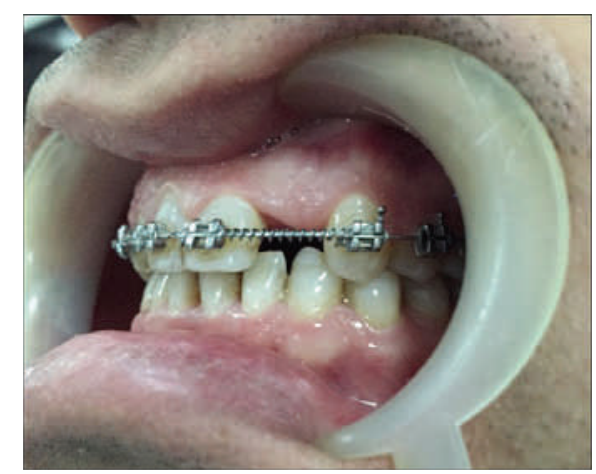

Figure 1: Orthodontic appliance showing NiTi pushing spring.

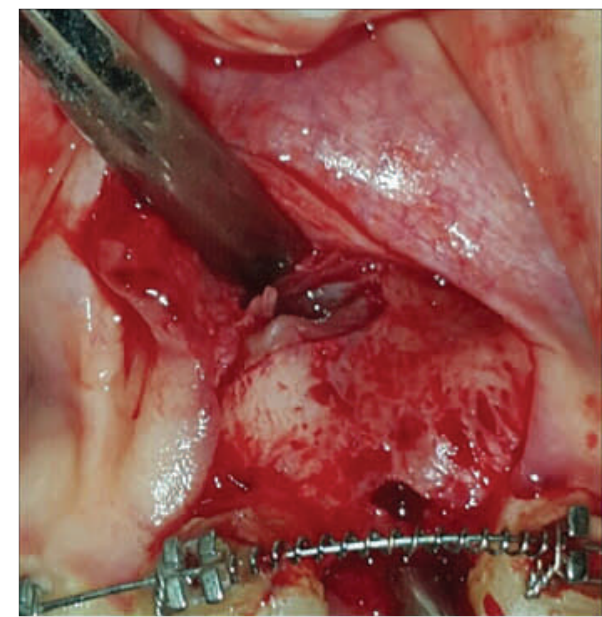

Figure 2: Drilling the implant site, periapical approach for bed curetting. 


\section{Results}

Nineteen female (63.3\%) and 11 male (36.67) patients participated in the study. Mean age of the patients was 26.33. Fifty implants used for replacement of their lost teeth. Maxillary lateral incisor region was the most common. Eleven implants failed to osseointegrate $(22 \%)$. Five implants showed early loss during the healing period. Most of the failed implants were in mandible. A new one replaced all the failed implants. Table 1 shows the distribution, success and failure of the implants. After cementation of the crown, the orthodontic appliances were removed and lingual wire used for retention period.

\section{Discussion}

Orthodontic tooth movement can play an important role in solving the problem of lost tooth space and formation of new bone for replacement. This study showed a lesser success rate of implants placed in orthodontically created space when compared to conventional methods (pre-existing bone). No similar studies found for comparison. The reason may be that the osteoclasts create a demineralized bony matrix through which the teeth can move easily, whereas the osteoblast maintains bone volume. The new bone remains immature until full remodeling of the bone has taken place. It is the combination of demineralized bone matrix and immature, uncalcified bone. ${ }^{11}$ Maxillary lateral incisor was the commonest missing tooth followed by maxillary canines. The higher success rate found in the region of lateral incisor. Similar results reported by other authors. ${ }^{1-6,12-15}$ This may be attributed to the fact that, when canine erupts next to the central incisor, favorable conditions affect the formation of the bone mass through distalization of the canine at the site of the missing lateral incisor. ${ }^{12}$ Mandibular region showed more failure rates. This may be attributed to the more dense cortical bone of the mandible, which mandates the use of heavy forces, which in turn lead to the formation of sterile necrotic bone (Hyalinized zone). ${ }^{16}$ The small sample size limits this study. This study is also limited by placing the implants immediately after space creation, i.e. no sufficient time was offered for complete bone remodeling. This insufficient remodeling time may be the cause of increased failure rate. So giving sufficient time for bone remodeling (higher bone quality) and slower orthodontic force for tooth movement may raise the chance of osseointegration of dental implants.

Table 1: The success rate of dental implants inserted in orthodontically created spaces.

\begin{tabular}{lccc}
\hline Replaced tooth by implant & Frequency (\%) & Success & Failure frequency \\
\hline Upper central incisor & $3(6 \%)$ & 1 & 2 \\
Upper lateral incisor & $15(30 \%)$ & 15 & 0 \\
Upper canine & $12(24 \%)$ & 10 & 2 \\
Upper 1st premolar & $2(4 \%)$ & 2 & 0 \\
Upper 2nd premolar & $1(2 \%)$ & 1 & 0 \\
Lower central incisor & $4(8 \%)$ & 1 & 3 \\
Lower lateral incisor & $6(12 \%)$ & 5 & 1 \\
Lower canine & 0 & 0 & 0 \\
Lower 1st premolar & 0 & 0 & 0 \\
Lower 2nd premolar & $7(14 \%)$ & 4 & 3 \\
Total & $50(100 \%)$ & $39(78 \%)$ & $11(22 \%)$ \\
\hline
\end{tabular}




\section{Conclusion}

Orthodontic treatment can be used as a type of osteodistraction method for provision of an acceptable amount of bone for dental implants. The quality of the gained bone can be improved by offering sufficient time for healing.

\section{Conflicts of interest}

The authors report no conflicts of interest.

\section{References}

1. Romeo E, Chiapasco M, Ghisolfi M, Vogel G. Long-term clinical effectiveness of oral implants in the treatment of partial edentulism. Seven-year life table analysis of a prospective study with ITI dental implants system used for single-tooth restorations. Clin Oral Implants Res 2002; 13:133 $-43$.

2. Lombardi R. The principles of visual perception and their clinical application to dental esthetics. J Prosthet Dent 1979; 9: 358-81.

3. Covani U, Crespi R, Cornelini R, Barone A. Immediate implants supporting single crown restoration: a 4 year prospective study. J Periodontol 2004; 75:982-8.

4. Sadan A, Blatz MB, Salinas TJ, Block MS. Single-implant restorations: a contemporary approach for achieving a predictable outcome. J Oral MaxillofacSurg 2004; 62:73-81.

5. Vermylen K, Collaert B, Linden U, Bjorn AL, De Bruyn H. Patient satisfaction and quality of single-tooth restorations. Clin Oral Implants Res 2003; 14:119-24.

6. Garber DA, Salama MA, Salama $H$. Immediatetotaltooth replacement. Compend ContinEduc Dent 2001; 22:210-8.

7. Mayer TM, Hawley CE, Gunsolley JC, Feldman S. The single-tooth implant: a viable alternative for single-tooth replacement. J Periodontal 2002; 73:687-93.

8. Weng D, Jacobson Z, Tarnow D, Hurzeler MB, Faehn O, Sanavi F, et al. A prospective multicenter clinical trial of $3 i$ machined-surface implants: results after 6 years of follow-up. Int J Oral Maxillofac Implants 2003; 18:417-23.

9. Noack N, Willer J, Hoffmann J. Long-term results after placement of dental implants: longitudinal study of 1,964 implants over 16 years. Int J Oral Maxillofac Implants 1999; 14:748-55.

10. Korayem M, Flores-mir C, Nassar U, Olfert K. Implant Site Development by Orthodontic Extrusion. Angle Orthodontist 2008; 4: 752-60.

11. McBride MD, Campbell PM, Opperman LA, Dechow PC, Buschang PH. How does the amount of surgical insult affect bone around moving teeth?Am J OrthodDentofacialOrthop 2014; 145(4 Suppl): S92-9.
12. Nováčková S, Marek I, Kamínek M. Orthodontic tooth movement: Bone formation and its stability over time. Am J OrthodDentofacialOrthop 2011; 139:37-43.

13. Thilander B, Persson M, Adolfsson U. Roentgen-cephalometric standards for a Swedish population. A longitudinal study between the ages of 5 and 31 years. Eur J Orthod 2005; 27:370-89.

14. Thilander B, Odman J, Jemt T. Single implants in the upper incisor region and their relationship to the adjacent teeth. An 8-year follow-up study. Clin Oral Implants Res 1999; 10:346-55.

15. Dickinson G. Space for missing maxillary lateral incisors orthodontic perceptions. Ann R Australas Coll Dent Surg2000; 15: 127-31.

16. Gündüz E, Carlos, Torres $C R$, Gahleitner A, Heissenberger G, Bantleon HP. Bone regeneration by bodily tooth movement: dental computed tomography examination of a patient. Am J Orthod Dentofacial Orthop 2004; 125 : 100-6. 